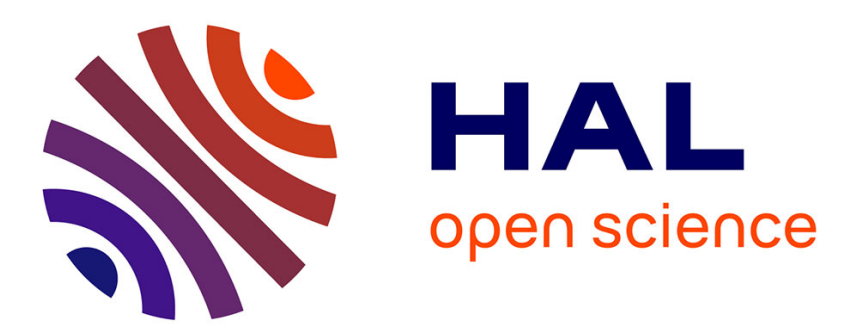

\title{
Microstructural design of platelet reinforced ceramics
}

\author{
W. Pompe, D. Wilkinson
}

\section{To cite this version:}

W. Pompe, D. Wilkinson. Microstructural design of platelet reinforced ceramics. Journal de Physique IV Proceedings, 1993, 03 (C7), pp.C7-1889-C7-1894. 10.1051/jp4:19937302 · jpa-00251946

\section{HAL Id: jpa-00251946 https://hal.science/jpa-00251946}

Submitted on 1 Jan 1993

HAL is a multi-disciplinary open access archive for the deposit and dissemination of scientific research documents, whether they are published or not. The documents may come from teaching and research institutions in France or abroad, or from public or private research centers.
L'archive ouverte pluridisciplinaire HAL, est destinée au dépôt et à la diffusion de documents scientifiques de niveau recherche, publiés ou non, émanant des établissements d'enseignement et de recherche français ou étrangers, des laboratoires publics ou privés. 


\title{
Microstructural design of platelet reinforced ceramics
}

\author{
W. POMPE and D.S. WILKINSON*
}

Research Group "Mechanics of Heterogeneous Solids" of the Max-Planck-Society, Technical University Dresden, Hallwachsstr. 3, 8027 Dresden, Germany

* Department of Materials Science and Engineering, McMaster University, Hamilton, Ontario, L8S 4L7, Canada

\begin{abstract}
Platelet reinforcement can increase the fracture toughness of ceramics. However, the responsible mechanisms are still not clearly understood. In this paper we examine the role of residual stresses due to thermal expansion mismatch. The residual stress distribution can be calculated using the effective-field approximation for ellipsoidal inclusions. The three main toughening mechanisms (crack deflection, crack bridging, and microcracking) are affected differently by residual stresses. We show how the critical flaw size can be properly assessed once the role of residual stress is taken into account, and how the flaw size is related to microstructural features in the material. It follows that by optimizing the ratio of grain size to platelet size, and by controlling the residual stress distribution, the fracture toughness can be increased by platelet reinforcement by more than $50 \%$ without a significant decrease in strength.
\end{abstract}

\section{The Problem}

A wide range of platelet-reinforced ceramics have been developed over the last five years [1-8]. Platelets provide an alternative to whisker reinforcement, as a means of improving the fracture toughness and high temperature creep resistance of ceramic materials. Moreover, platelet reinforcement offers certain advantages over whiskers, such as:

a) the availability of less expensive reinforcement materials without the health hazards associated with whiskers, in a range of materials including $\mathrm{Al}_{2} \mathrm{O}_{3}, \mathrm{SiC}$ and $\mathrm{B}_{4} \mathrm{C}$;

b) the higher thermal stability of platelets and a reduced density of structural defects; and

c) enhanced pullout behaviour.

However platelet reinforcement also involves some disadvantages, such as the larger flaws which develop due to the two-dimensional thermoelastic mismatch. Thus, fracture toughness increases following the incorporation of platelets in a ceramic matrix are often accompanied by a drop in fracture strength. Such behaviour is far from universal however, with some systems exhibiting both strength and toughness improvement with the addition of platelets[7].

The effect of reinforcement on fracture toughness and strength depends on a number of microstructural parameters including the volume fraction, the size, aspect ratio and orientation [8] of the platelets, the nature of the matrix/platelet interface, and residual stresses developed due to the thermal mismatch between platelet and matrix. In this paper we focus on the latter. We will show that the micromechanical behaviour of a composite depends on the combined thermoelastic properties of various platelet/matrix combinations. We will focus on four specific systems, for which the coefficient of thermal expansion (CTE) mismatch $\Delta \alpha=\alpha_{\mathrm{p}}-\alpha_{\mathrm{m}}$ between the platelet $\left(\alpha_{\mathrm{p}}\right)$ and matrix $\left(\alpha_{\mathrm{m}}\right)$ ranges from negative to positive, including one case in which $\Delta \alpha$ is close to zero. It will be shown that the CTE influences the microstress distribution, which then controls which toughening mechanisms are available to the composite. Additionally, the nature of the critical flaws is affected. Thus fracture toughness and strength can be optimized by the formation of an appropriate residual stress state. In particular, the effect of processing temperature and post-processing heat treatment on toughness improvement will be analyzed. 


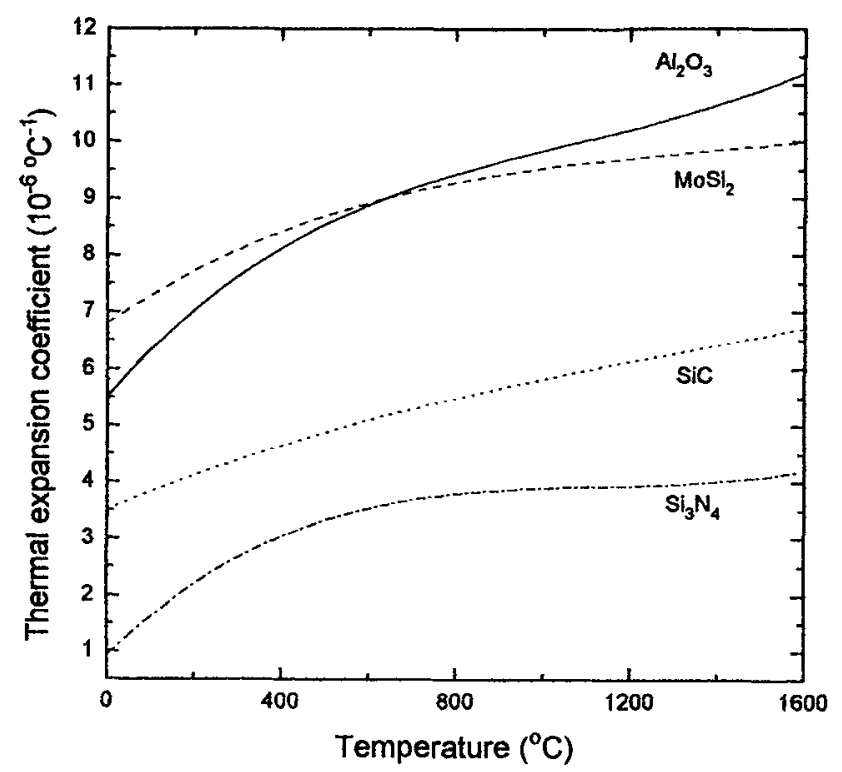

Fig.1: Temperature dependence of the coefficient of thermal expansion for materials relevant to this study.

\section{Residual stresses in platelet reinforced ceramics}

Our theoretical considerations will be focussed on understanding the measured mechanical behaviour of $\mathrm{SiC}$ platelets in $\mathrm{Al}_{2} \mathrm{O}_{3}[4,8]$ and $\mathrm{Si}_{3} \mathrm{~N}_{4}$ [10] matrices and also of $\mathrm{Al}_{2} \mathrm{O}_{3}$ platelets in $\mathrm{MoSi}_{2}$ [7] and $\mathrm{ZrO}_{2}$ [11]. The processing routes and mechanical properties of these materials have been described in the above mentioned papers. As we see from the CTE data (Fig.1) these systems represent three different types of thermoelastic behaviour:

$$
\begin{aligned}
& \text { (i) } \mathrm{SiC}_{(\mathrm{pi})}-\mathrm{Si}_{3} \mathrm{~N}_{4} \quad \alpha_{\mathrm{p}}>\alpha_{\mathrm{m}} \\
& \text { (ii) } \mathrm{Al}_{2} \mathrm{O}_{3(\mathrm{pl})}-\mathrm{MoSi}_{2} \quad \alpha_{\mathrm{p}} \approx \alpha_{\mathrm{m}} \\
& \text { (iii) } \mathrm{SiC}_{(\mathrm{p})}-\mathrm{Al}_{2} \mathrm{O}_{3}, \quad \mathrm{Al}_{2} \mathrm{O}_{3(\mathrm{pl})}-\mathrm{ZrO}_{2} \quad \alpha_{\mathrm{p}}<\alpha_{\mathrm{m}}
\end{aligned}
$$

Whereas in case (i) the average residual stresses are tensile in the platelets, and compressive in the matrix, in case (iii) the opposite situation is given. Case (ii) represents a near residual stress-free state. In order to understand the micromechanical behaviour in more detail, the local microstress distribution must be considered. The average stresses in the platelets and the matrix can be described with a statistical approach [9], from which we get, for the isotropic part of the stress tensor,

$$
s_{p}=-3 v_{m} \frac{\left(\boldsymbol{\alpha}_{p}-\boldsymbol{\alpha}_{m}\right) \Delta T}{\left(V_{p} / K_{m}+V_{m} / K_{p}+3 / 4 G_{m}\right)} \quad, \quad s_{m}=-\frac{v_{p}}{V_{m}} s_{p}
$$

where $\mathrm{v}, \mathrm{K}, \mathrm{G}$ are the volume fraction, bulk modulus and shear modulus respectively, and $\Delta \mathrm{T}$ is the temperature difference on going from the stress-free state to room temperature. The shape influence on the local residual stress field can be modeled by applying a generalization of the Eshelby approach, as shown by Kreher and Janssen [10]. Here, a platelet is treated as a disk-like spheroidal inclusion with axes $a_{1}=a_{2} \neq a_{3}$ and aspect ratio $\psi=a_{1} / a_{3}$. The effect of volume fraction is treated by considering single platelets embedded in an effective composite medium. Figure 2 shows an example of the matrix stress distribution for case (i). The stresses are calculated at two positions - along the platelet edge, point $\mathrm{A}=\left(0, \mathrm{a}_{2}, 0\right)$, and on the platelet face, at point $\mathrm{C}=$ $\left(0,0, a_{3}\right)$. As the normal stresses must be continuous at the interface, $\sigma_{\mathrm{rr}}$ also gives the constant stresses inside the spheroidal platelet. The calculation shows that in case (i) the interfacial traction is tensile. Similarly, we can 
evaluate the stress distribution for case (iii). Not surprisingly, we get a local distribution with the opposite sign for all stresses. The absolute values scale with $\left(\alpha_{p}-\alpha_{m}\right) \Delta T$.

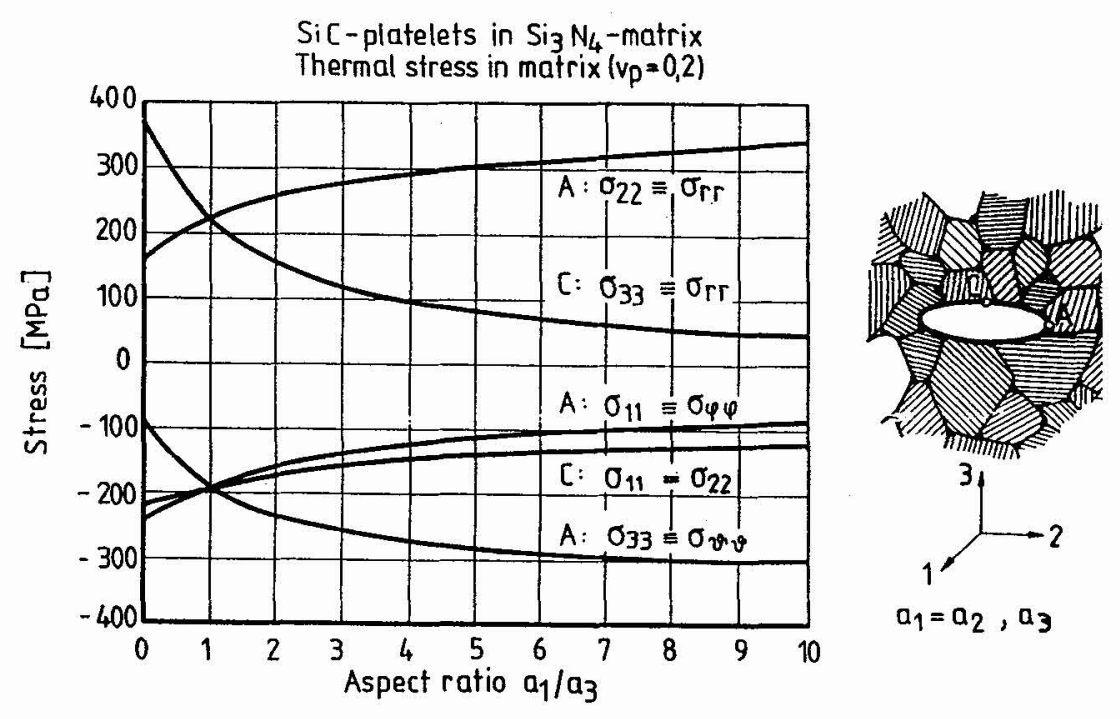

Fig.2: Stress distribution in a $\mathrm{Si}_{3} \mathrm{~N}_{4}$ matrix for two positions $\mathrm{A}$ and $\mathrm{C}$ at the $\mathrm{SiC}$ platelet interface [10]; a temperature difference of $1000 \mathrm{~K}$ between the stress-free state and room temperature is assumed.

\section{Toughening mechanisms and residual stress distribution}

Platelet reinforcement offers the possibility of using three different mechanisms for increasing the fracture toughness - namely, deflection of the crack tip [12,13], bridging of the crack wake behind the crack tip [13-16], and the formation of matrix microcracks near the crack tip $[17,18]$. Generally we assume that all three mechanisms may occur simultaneously. Ignoring interactions between the different mechanisms the total fracture toughness $G_{c}$ is given by

$$
G_{c}=G_{m}+\Delta G_{d e f 1}+\Delta G_{b r i d}+\Delta G_{d i s s}
$$

where $\mathrm{G}_{\mathrm{m}}$ is the fracture toughness of the unreinforced matrix, and $\Delta \mathrm{G}_{\text {defl }}, \Delta \mathrm{G}_{\text {brid }}$ and $\Delta \mathrm{G}_{\text {diss }}$ describe the increase due to crack deflection, bridging and microcracking, respectively. The importance of each toughening mechanism is different in each of the three cases. For example:

a) Crack deflection is favoured if the platelets are under compression while the interface is under tension (case (iii)). Crack deflection may also be observed in case (i), with a weak platelet-matrix interface. The fracture toughness increase $\Delta \mathrm{G}_{\text {def }}$ scales with $\mu_{\mathrm{d}} \mathrm{v}_{\mathrm{p}} \psi \gamma_{\mathrm{i}}$ where $\gamma_{\mathrm{i}}$ is a characteristic interfacial energy and $\mu_{\mathrm{d}}$ is a dimensionless factor of order 1 [12].

b) Crack bridging is relevant when the platelets are larger than the matrix grains and the matrix residual stress is zero or negative. Bridging platelets can transfer load across the crack wake by two different processes. Shear stress transfer is possible across the platelet-matrix interface when the platelets are either chemically bonded with the matrix, or clamped by a compressive residual stress or interface roughness. The increase of the fracture toughness $\Delta \mathrm{G}_{\text {brid }}$ scales with $\mu_{\mathrm{b}} \mathrm{v}_{\mathrm{p}} \tau_{0} \mathrm{l}_{\mathrm{p}}$ where $\tau_{0}$ and $\mathrm{l}_{\mathrm{p}}$ are the interface shear strength and platelet length respectively [13-15]. Non-frictional jamming of the platelets can occur if the platelets are tilted slightly with respect to the crack wake. A force is built up normal to the crack wake which is limited by the matrix fracture strength. As shown elsewhere [16] the fracture toughness increases with matrix strength $\sigma_{\mathrm{mf}}$ and platelet length, such that $\Delta \mathrm{G}_{\text {brid }}$ 
$=\left(1-v_{p}\right) \sigma_{m f}^{2} l_{p} / 16 E_{m}$. Therefore crack bridging can yield an increase of fracture toughness in cases (ii) and (iii). c) Microcracking occurs when in the matrix contains a tensile residual stress state. The stress concentration near the tip of the macrocrack is connected with the formation of microcracks in a zone around the crack tip - the socalled energy dissipation zone. This microcrack formation reduces the elastic energy near the crack tip (shielding). The size of the zone $2 r_{\eta}$ increases with the tensile residual stress in the matrix. For small-scale damage $r_{\eta}$ is given by $r_{\eta}=\mu_{\eta} G_{c} E_{m} / \sigma_{c}^{2}$, where $\sigma_{c}$ is the stress at which microcracking starts [17]. The critical energy release rate near the crack tip can be described by two terms - the energy dissipation due to microcracking $\eta_{\mathrm{d}}$, and the change of the stored elastic energy in the matrix during this microcracking $\Delta \eta_{\mathrm{s}}$. This gives $\Delta \mathrm{G}_{\text {dies }}=$ $2 \mathrm{r}_{\eta}\left(\eta_{\mathrm{d}}+\Delta \eta_{\mathrm{s}}\right)[17]$.

Microcracking occurs together with crack deflection when a tensile stress exists in the matrix. The total fracture toughness can be calculated for the combination of these two mechanisms from a summation of the three terms for $\mathrm{G}_{\mathrm{m}}, \Delta \mathrm{G}_{\mathrm{defl}}$ and $\Delta \mathrm{G}_{\text {diss }}$, giving

$$
\frac{G_{C}}{2 \gamma_{m}}=\frac{\left(1+\mu_{d} v_{p} \psi\right) \gamma_{i} / 2 \gamma_{m}}{1-\mu_{\eta} \frac{\eta_{d}+\Delta \eta_{s}}{\sigma_{c}^{2} / 2 E_{m}}}
$$

Here $2 \gamma_{\mathrm{m}}$ denotes the fracture toughness of the unreinforced matrix $\mathrm{G}_{\mathrm{m}}$. Both $\Delta \eta_{\mathrm{s}}$ and $\sigma_{\mathrm{c}}$ depend on the residual stress in the matrix. A detailed analysis for these terms has been developed for particulate inclusions [17]. Similar dependencies are valid for inclusions with platelet geometry. For sake of simplicity we adopt approximate solutions given by

$$
\Delta \eta_{s}=-v_{p} k \zeta^{2} \frac{\sigma_{m f}^{2}}{E_{m}} \quad, \quad \frac{\sigma_{c}}{\sigma_{m E}}=(1-\zeta)
$$

Here $\varsigma$ denotes the change of the matrix fracture strength due to residual stresses, while $\mathrm{k}$ summarizes the interaction of microcracks with the surrounding medium (i.e. loss of modulus). The results of this calculation are shown in Fig. 3. The residual stress produces two opposing effects. As it increases so does the zone of energy dissipation leading to higher toughness. However this is counterbalanced by a reduction in the stored elastic energy released. Thus there exists an optimum level for the residual stress which yields maximum fracture toughness.

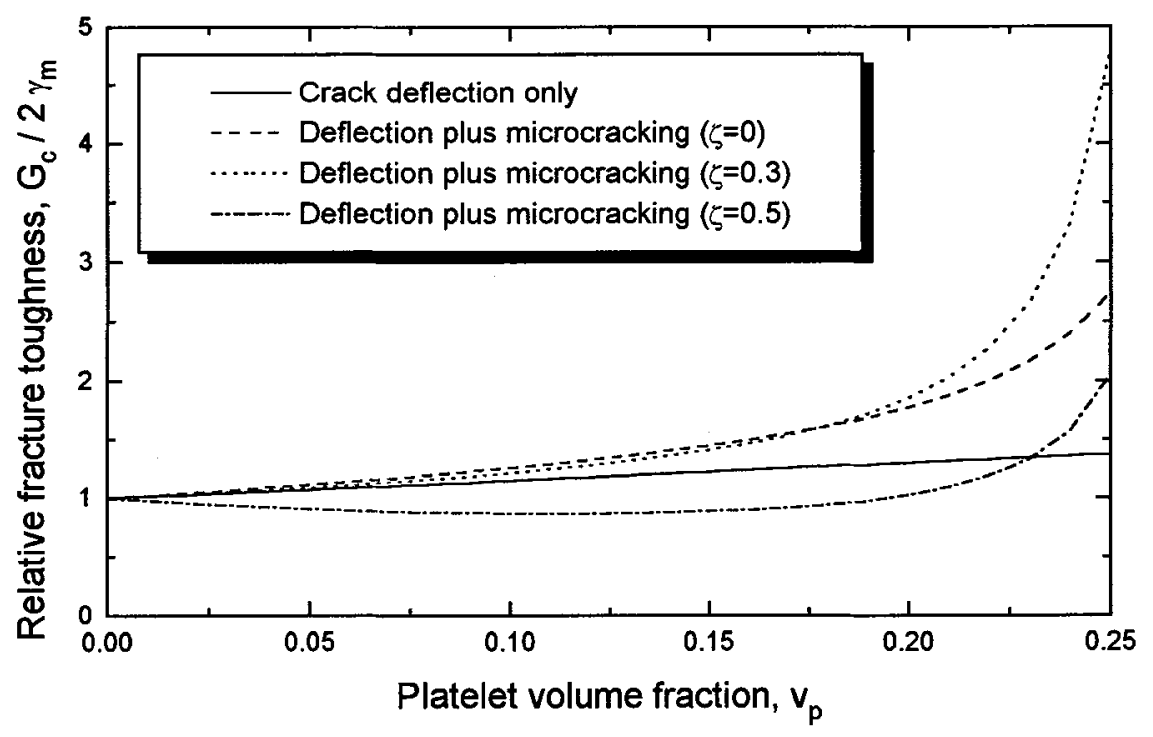

Fig.3: The fracture toughness $G_{c} / 2 \gamma_{m}$, for a combination of crack deflection and matrix microcracking, as a function of platelet volume fraction $v_{p}$ for different residual stresses (and assumimg $\gamma_{i} / 2 \gamma_{m}=1$ ). 


\begin{tabular}{|c|c|c|c|c|c|c|c|c|}
\hline $\begin{array}{l}\text { Composite } \\
\text { system }\end{array}$ & $v_{p}$ & $\underset{\mathbf{M P a m}^{1 / 2}}{\mathbf{K}_{\mathrm{c}}}$ & $\begin{array}{l}\sigma_{\mathrm{f}} \\
\mathrm{MPa}\end{array}$ & $\begin{array}{c}\sigma_{\text {res }} \\
\mathrm{MPa}\end{array}$ & $\begin{array}{l}d_{\text {graim }} \\
\mu \mathrm{m}\end{array}$ & $\underset{\mu \mathrm{m}}{\mathrm{l}_{\mathrm{p}}}$ & $\begin{array}{c}\mathrm{c} \\
\mu \mathrm{m}\end{array}$ & $\begin{array}{l}\mathrm{c}_{\text {crit }} \\
\mu \mathrm{m}\end{array}$ \\
\hline \multirow{7}{*}{$\begin{array}{l}\text { Case (i): } \\
\mathrm{SiC} / \mathrm{Si}_{3} \mathrm{~N}_{4}\end{array}$} & 0 & 4.9 & 700 & 0 & $1-2$ & - & 30 & 30 \\
\hline & 0.1 & 5.4 & 350 & 300 & $1-2$ & 70 & 150 & 43 \\
\hline & 0.2 & 5.9 & 350 & 300 & $1-2$ & 70 & 179 & 51 \\
\hline & 0.3 & 6.3 & 350 & 300 & $1-2$ & 70 & 204 & 59 \\
\hline & 0.1 & 5.6 & 650 & 300 & $1-2$ & 12 & 47 & 21 \\
\hline & 0.2 & 6.0 & 520 & 300 & $1-2$ & 12 & 83 & 34 \\
\hline & 0.3 & 6.5 & 520 & 300 & $1-2$ & 12 & 98 & 40 \\
\hline \multirow{2}{*}{$\begin{array}{l}\text { Case (ii): } \\
\mathrm{Al}_{2} \mathrm{O}_{3} / \mathrm{MoSi}_{2}\end{array}$} & 0 & 3.1 & 145 & 0 & 8 & $10-15$ & 288 & 288 \\
\hline & 0.25 & 4.8 & 265 & 0 & 8 & $10-15$ & 207 & 207 \\
\hline \multirow{6}{*}{$\begin{array}{l}\text { Case (iii): } \\
\mathrm{SiC} / \mathrm{Al}_{2} \mathrm{O}_{3}\end{array}$} & 0 & 2.98 & 710 & 150 & $0.5-1$ & - & 11 & 7.6 \\
\hline & 0.1 & 2.81 & 615 & 500 & $0.5-1$ & 15 & 13 & 4 \\
\hline & 0.2 & 2.88 & 530 & 500 & $0.5-1$ & 15 & 18 & 5 \\
\hline & 0 & 4.2 & 600 & 150 & $2-5$ & - & 31 & 20 \\
\hline & 0.1 & 5.3 & 400 & 500 & $2-5$ & $3-20$ & 112 & 22 \\
\hline & 0.15 & 6.8 & 370 & 500 & $2-5$ & $3-20$ & 216 & 39 \\
\hline \multirow{3}{*}{$\begin{array}{l}\text { Case (iii): } \\
\mathrm{Al}_{2} \mathrm{O}_{3} / \mathrm{ZrO}_{2}\end{array}$} & 0 & 5 & 1550 & 0 & 1 & - & 6.6 & 6.6 \\
\hline & 0.05 & 6.8 & 700 & 1000 & 1 & $30-40$ & 59 & 10 \\
\hline & 0.1 & 6.2 & 650 & 1000 & 1 & $30-40$ & 57 & 8.9 \\
\hline
\end{tabular}

\section{Comparison with the experiment}

Table I summarizes experimental data for the effect of platelet additions on strength and fracture toughness. The generally observed increase of the fracture toughness is consistent with the theoretical estimate of the toughening potential as just discussed. Moreover, microscopic observations of crack propagation and of fracture surfaces show that different processes occur in different materials. Additionally it has been shown for a single material $\left(\mathrm{SiC}-\mathrm{Al}_{2} \mathrm{O}_{3}\right.$ ), that the fracture toughness can be increased by a heat treatment which raises the level of residual stress in the composite [8]. This is accompanied by the onset of microcracking, illustrating the importance of this mechanism to toughening in this case.

We have calculated the critical flaw size $c$ from the experimental data, assuming a semi-circular surface crack. It is given by $c=\left(\mathrm{K}_{c} / \xi \sigma_{f}\right)^{2}$ where $\sigma_{\mathrm{f}}$ is the macroscopic failure strength, and the compliance function $\xi$ is equal to 1.25 [19]. The critical stress intensity factor has been measured independently and can be related to the models discussed above using the well know relationship $G_{c}=K_{c}{ }^{2} / E_{c}$ (where $E_{c}$ is the Young's modulus of the composite), which reflects the changing residual stress distribution on a macroscopic scale. However, this relationship does not adequately incorporate the influence of residual stress, since the local stress initiating crack propagation also depends on the residual stress. Fractography shows that the failure origins in platelet-reinforced ceramics are invariably associated with individual platelets. This has often been taken to show that the platelets themselves act as fracture initiation sites. However, it is also possible that failure occurs in the matrix, but in the vicinity of a platelet due to the enhanced local stress filed. In this case, the total stress at the crack tip is given by a superposition of the external load and the residual stress in the matrix near a platelet. If we assume that the microstress field varies on a length scale which is comparable with the critical flaw size, then a better estimate of the critical flaw size $c_{\text {crit }}$ is given by 


$$
C_{c r i t}=\frac{K_{c}^{2}}{\xi^{2}\left(\sigma_{f}+\sigma_{r e s}\right)^{2}}
$$

where $\sigma_{\text {res }}$ denotes the value of the residual stress near the crack tip. This has been incorporated into the flaw analysis using estimates for the residual stress in the vicinity of the platelets as appropriate, i.e. taking into account the different initiation sites appropriate to cases (i) - (iii). We have used the simplest possible analysis here, based on the residual stress around a single isolated platelet (i.e. ignoring possible volume fraction effects). The results of this calculation are shown in Table $\mathbf{I}$. The analysis shows that the critical flaw size calculated including the influence of residual stress are more consistent with the microstructure than the uncorrected flaw sizes, i.e the critical flaw size varies much less as a function of the volume fraction of platelets $v_{p}$. Moreover, we observe that the critical flaws are connected with different structural features, depending on the nature of the residual stress state. For example, when the platelets are under tension (as in case (i)), cracks can easily be nucleated at the platelet/matrix interface and the flaw size is equal to the platelet diameter, so long as the platelets are larger than the natural flaw size of the matrix. However, when the platelets are under compression (as in case (iii)), the platelets themselves do not act as flaws. They simply provide regions of high residual stress which enhance the propagation of matrix flaws. The flaw size is therefore given by the critical flaw size of the matrix, even if the platelet size is larger than the critical matrix flaw. This is clealry shown in the table with reference to both the $\mathrm{SiC}-\mathrm{Al}_{2} \mathrm{O}_{3}$ and the $\mathrm{Al}_{2} \mathrm{O}_{3}-\mathrm{ZrO}_{2}$ systems.

This suggests two rather different strategies which can be employed in order to optimize the strength of plateletreinforced ceramics. For composites of the type given by case (i), the platelet diameter should be kept small, i.e. at or below the natural flaw size of the matrix. For case (iii) type systems however, strength degradation can be restricted by minimization of the matrix grain size (and thus the matrix flaw size). Such composites offer the possibility of simultaneously increasing the fracture toughness and failure strength. This requires that the residual stress be in the range required for optimum fracture toughness (see Fig. 3), while the matrix grain size should be relatively small. The strength of the platelet-matrix interface should also be low. Then this interface can act as a source for extended crack deflection, as well as for microcracking of the matrix.

\section{References}

[1] CLAUSSEN N., in: Structural Ceramics - Processing, Microstructure and Properties, ed.J.J.Bentzen, J.B.Bilden-Sorenson, et al., Riso National Laboratory, Roskilde, Denmark (1990) 1-12.

[2] ZHENG X.Y., ZENG F.P., POMEROY M.J., HAMPSHIRE S., Brit.Ceram.Proc. 45 (1990) 187-198.

[3] JANSSEN R., HEUSSNER K.-H., Powd.Met.Int. 23 (1991) 241-245.

[4] CLAASSEN T.,CLAUSSEN N., J.Eur.Ceram.Soc. 10 (1992) 263-271.

[5] CHOU Y.S., GREEN D.J., J.Am.Ceram.Soc. 75 (1992) 3346-3352.

[6] BARIL D., JAIN M.K. Ceram.Eng.Sci.Proc. 12 (1991) 1175-1192.

[7] TUFFE S.C., PLUCKNETT K.P., WILKINSON D.S., Ceram.Eng.Sci.Proc. 14 (1993) in press

[8] BLOYCE D.M., HAM-SU R., PLUCKNETT K.P., WILKINSON D.S., Proc. Symp. on Ceramic Matrix Composites, ed.N.P.Bansal (Amer.Ceram.Soc.)1993, in press.

[9] KREHER W., POMPE W., Internal Stresses in Heterogeneous Solids, Akdemieverlag, Berlin, 1989.

[10] KREHER W., JANSSEN R., J. Eur. Ceram. Soc. 10 (1992) 167-173.

[11] HEUSSNER, K.-H., J. Eur. Ceram. Soc., 5 (1989) 193-200.

[12] FABER K.T.,EVANS A.G., Acta Metall.31 (1983) 565-576 and 577-584.

[13] CAMPELL G.H., RUEHLE M., DALGEISH B.J., EVANS A.G., J.Am.Ceram.Soc.73 (1990)521-530

[14] RITCHIE R.O., Mater.Sci.Eng. A103 (1988) 15-28.

[15] BECHER P.F., HSEUSH C.H., ANGELINI P., TIEGS T.N., J.Am.Ceram.Soc. 71 (1988) 1050-1061.

[16] WEISS H.-J., J.Eur. Ceram. Soc. 10 (1992) 161-165.

[17] POMPE W., BAHR H.-A. et al., in: Current Topics in Materials Science, vol.12, ed. Kaldis E., North Holland, Elsevier, Amsterdam, 1985.

[18] RUEHLE M., EVANS A.G.,Progress in Materials Science 33 (1989) 85-167.

[19] BROEK, D., Elementary Engineering Fracture Mechanics, Martinu Nijhoff Publishers, Boston, 1982. 